\title{
A systematic review of occupant behavior in building energy policy
}

\author{
Shan $\mathrm{Hu}^{\text {a }}$, Da Yan ${ }^{\text {a, * }}$, Elie Azar ${ }^{\mathrm{b}}, \mathrm{Fei} \mathrm{Guo}^{\mathrm{c}}$ \\ ${ }^{a}$ Building Energy Research Center, School of Architecture, Tsinghua University, Beijing, China \\ ${ }^{b}$ Industrial and Systems Engineering Department, Khalifa University, United Arab Emirates \\ ${ }^{c}$ International Institute for Applied Systems Analysis, Austria \\ * Corresponding author: Building Energy Research Center, School of Architecture, Tsinghua University, Beijing, \\ 100084, China, Telephonelfax mumber:86 010-62785460,E-mail: yanda@tsinghua.edu.cn
}

\begin{abstract}
Buildings play a dominant role in global efforts towards energy consumption reduction, greenhouse gas (GHG) emission mitigation, as well as global clean energy transition. Building Energy Policies (BEP) improved globally and quickly with a growing number of building codes implemented over the past decade. Occupant Behavior (OB) has significant impacts on building energy performance and occupant comfort, despite often being not well understood and oversimplified in BEPs. This paper highlighted the research needs of properly integrating OB in building energy polices by presenting a literature review to identify the key questions and challenges related to building technical standards and regulations, building information policies, building energy incentives, and policy evaluations and way forward. Challenges and opportunities of OB in BEP are also discussed with respect to technical innovation and digitalization, as well as concerns related to energy efficiency and fairness. There has been growing interests, research and applications in this field, but significant challenges and opportunities still lie ahead.
\end{abstract}

Keywords: Occupant behavior; building energy policy; climate change policy; building energy efficiency; HVAC system

\section{Introduction}

\subsection{Occupant behavior in building energy policy}

Buildings play a dominant role in global efforts towards energy consumption reduction, greenhouse gas (GHG) emission mitigation, as well as global clean energy transition. Facing global climate change and national energy security challenges, international agreements, initiatives, and building sector energy policies are providing 
promising alternatives to the status quo. In recent years, Building Energy Policies (BEP) improved globally and quickly with a growing number of building codes implemented over the past decade. In contrast, global final energy consumption in buildings increased by more than 5\% between 2010 and 2017, as energy efficiency gains were outpaced by continued growth in the building sector size and resulting energy service demands [1]. Among various factors, Occupant Behavior (OB) plays an essential role in building energy demand increases and activity growth. In addition, OB has significant impacts on building energy performance and occupant comfort, despite often being not well understood and oversimplified in BEPs due to its stochastic, diverse, complex and interdisciplinary nature [2]. Definition, estimation and intervention of OB become essential research challenges during building energy policy making, implementation and evaluation processes.

Figure 1 illustrates a schematic of the interactions between building energy performance status, BEP, and OB. This figure was redesigned based on a figure explaining market transformation approach from GBPN (Global Buildings Performance Network) [3]. Considering building stocks with diversified building energy performance levels, the purpose of BEPs is to decrease the number of "illegal" buildings (i.e., exceeding minimum energy performance requirements), maintain most buildings complying with acceptable performance requirements, and encourage buildings to achieve higher-performance levels through technological innovations [4], as shown in Figure 1.

Energy policies are normally divided into sticks, tambourines, and carrots [5]. In the context of the building sector: (i) "sticks in BEP" are regulations, codes and standards, which provide benchmarking metrics and indices of illegal performance in buildings, as well as disclosure mechanisms that reveal such information to discourage these phenomena; (ii) "tambourines in BEP" are information tools such as capacity building, labelling, and awareness-raising campaigns that educate the public on compliance requirements and energy saving strategies; and (iii), "carrots in BEP" are incentives such as rebates and subsidies to encourage outstanding building performance through either technological innovation or curtailment practices (i.e., conservative OB). In many countries, integrated policies combing the three types of mechanisms (presented above) effectively promoted improvements in building energy performance.

In practice, building occupants proactively interact with their built environment and service systems, constantly seeking what they perceive as comfortable indoor conditions. Consequently, OB is often recognized as a major source of building performance uncertainty. OB's role in BEP has risen further in relative terms as comfort expectations are constantly increasing, along with the growing push towards efficiency in lighting, building envelopes, and heating, ventilation, and air-conditioning (HVAC) systems [6]. Effective regulation requires the estimation of default, or reference, OB (i.e., default setting on indoor temperature, fresh air volume per person, water usage amount per person, operating hours of space heating and space cooling), raising the first question of $\mathrm{OB}$ in $\mathrm{BEP}$ research, which is how to define and choose standard OB for use as default or benchmark value for assessment? The overall difficulties of BEP regarding OB is how to estimate OB distribution in population with a view on the diversity and stochastic features of OB. Such knowledge is essential to guide mechanisms, such as information tools and incentives, which increase cognition of $\mathrm{OB}$ and eventually alter it despite its multidisciplinary and complex nature. 


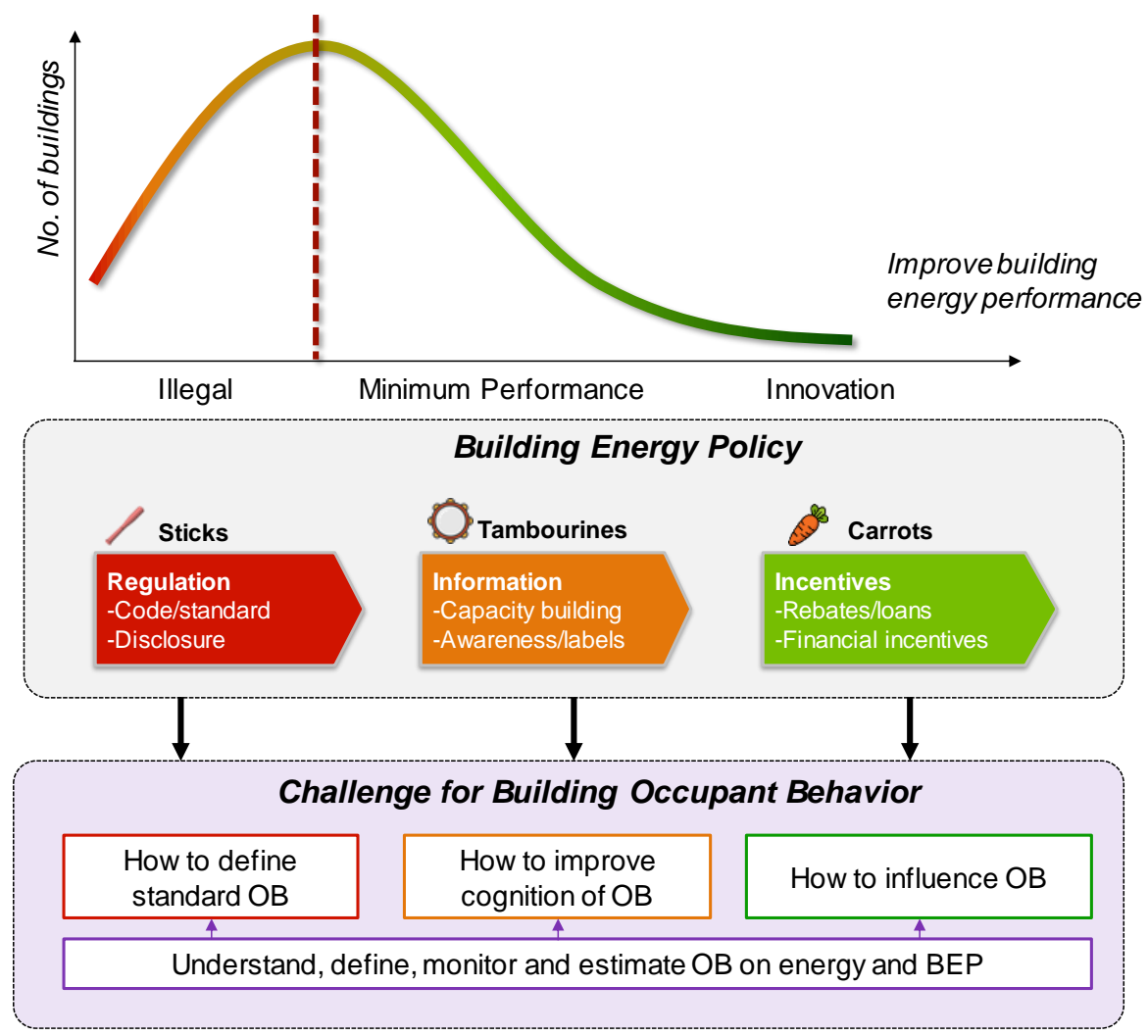

Figure 1 Interactions of building occupant behavior with building energy policies[3]

\subsection{Review objective and framework}

This paper presents a review of the literature on occupant behavior (OB) in building energy policy (BEP) to identify the key questions and challenges related to building technical standards and regulations, building information policies, building energy incentives, and BEP evaluations and way forward. The paper highlights research barriers to fully and holistically integrating OB in BEP. Challenges and opportunities of OB in BEP are also discussed with respect to technical innovation and digitalization, as well as concerns related to energy efficiency and fairness. Practical suggestions follow to better shape BEP with a proper consideration of OB.

Figure 2 presents the scope of the review and framework of research through a representation of the interaction loop connecting OB to BEP. Firstly, occupants proactively interact with building and systems resulting in building energy consumption and related emissions. The resulting pressure of energy security, environment protection, and climate change, BEPs are proposed and implemented, which in turn affect both building systems and $\mathrm{OB}$, closing the loop of $\mathrm{OB}$, building energy, and BEP. 


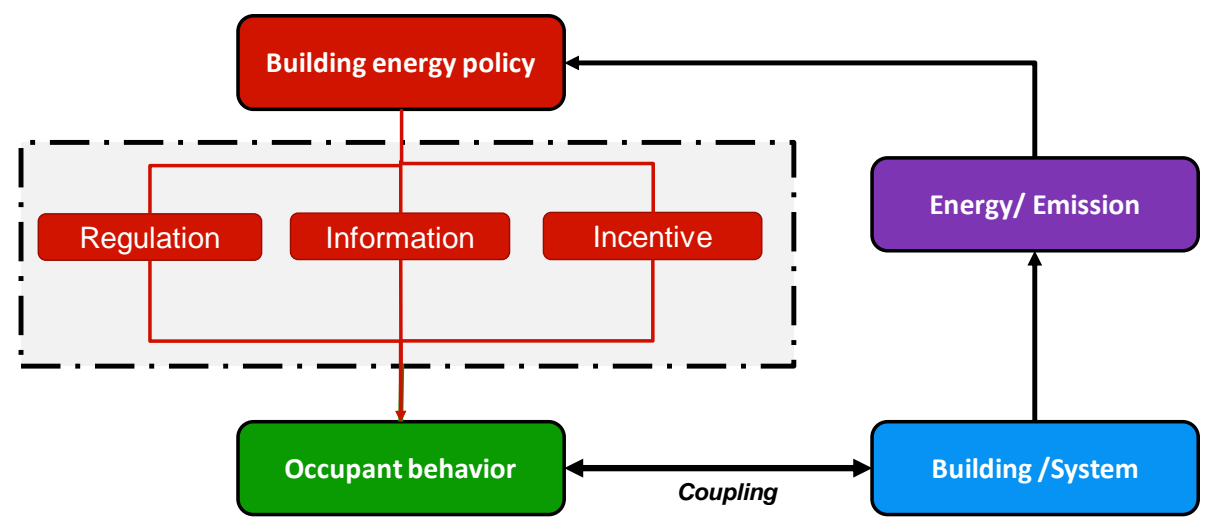

Figure 2 Review scope and framework of research

This review research follows a systematic review process. First, electronic searches of relevant publications on building energy polies and occupant behaviors were conducted in Google Scholar, Web of Science and Scopus database. Among all papers, classic papers which indicate original concept, review papers which provide research structures, highly cited and hot papers which reveal the research frontier were identified. These selected papers are reviewed first, to summarize the aim and scope of OB in BEP and establish the detailed review structure. Then searched manuscripts were screened and classified into the review framework, additional case study was also supplemented to fulfil the state of art on each sections, including building energy regulations, building energy information tools and building energy incentives. In these process, peer reviewed conference paper, report and working papers from authoritative research institutions were also included, since they include useful discussions on national-wide or world-wide building energy efficiency policies. For example, conference proceeding from ACEEE (American Council for an Energy-Efficient Economy) and ECEEE (European Council for an Energy Efficient Economy), and report from IEA (International Energy Agency) and IPCC (Intergovernmental Panel on Climate Change).The review framework and remainder of this article is organized as follows: Section 2 discusses the aim and state of art of OB in building energy regulation; Section 3 covers the aim and state of art of OB in building energy information intervention; Section 4 discusses the aim and state of art of OB in building energy related economic incentives; In Section 5, challenges and opportunities of OB in BEP are discussed followed by a conclusion in Section 6.

\section{Occupant behavior in building energy regulations}

\subsection{Aim and scope}

Historically, the occupant behavior related parameters were simplified and considered as a boundary condition like weather, instead of active participants in the buildings[7]. Nowadays, occupant behavior in buildings has drawn a surge of research attention, because more proofs were identified that energy use in buildings is closely linked to occupant presence, movement and interaction with building energy devices and systems[8-10]. Building energy regulations is one of the most influential and widely used ways to improve building energy performance[11-13].. The distribution of OB in specific population group represents the characteristics of this 
population. Therefore, representative OB are carefully selected from the real OB distribution, to be used as OB in building energy related regulations. Normally, the selected OB represents the average status or most probable OB among the specific population[7,8]. However, homogeneity and heterogeneity, as well as uncertainly exist in building $\mathrm{OB}[9,14-16]$.

The target of investigating OB for building energy regulation is to: firstly, understand the general OB patterns and distribution; secondly, define typical OB patterns as a representation of certain population groups; and finally, adopt the typical $\mathrm{OB}$ as a design reference and basic assumption of building demand simulation, in turn guiding design choice further.

\subsection{Importance}

Building energy regulations are mainly focused on the energy performance at the building, system and equipment levels. From the building energy performance analysis with OB input, various design questions are crucial to achieve building energy efficiency, including: should building insulation be added? Which kind of equipment or system should be selected? How and at what capacity should the system be designed, such as capacity of chiller, boiler? Naturally, analysis with the real OB would lead to suitable building architecture design, system choice and equipment adoption, while analysis with deviated OB would lead to improper building design and choice of systems, eventually leading to high energy consumption and corresponding emissions.

It has been widely acknowledged in the literature that there is an alarming performance gap between the predicted and actual energy consumption of buildings due to OB factors[17].Gasps between selected OB with $\mathrm{OB}$ in reality are one of the most significant reasons leading to gaps between predicted and measured building energy performance were widely observed and researched in literatures[18-28]. Accurate understanding of real $\mathrm{OB}$, scientific method of choosing $\mathrm{OB}$, and proper definition of $\mathrm{OB}$ in building energy regulations are very essential to narrow the gap $[8,19]$. With proper design and effective implementation, building energy regulations can support energy cost savings and complementary benefits associated with electricity reliability, air quality improvement, greenhouse gas emission reduction, increased comfort, and economic and social development.

\subsection{State of art}

Occupants interacts with building, service system and appliances to reach their own personal desired indoor comfortable level. To achieve building energy conservation and emission reduction, regulations, standards and codes set requirements for building technologies and elements, which include: building envelope; HVAC systems; lighting; and domestic hot water heating system [29]. Researches on OBs in buildings now focus on three aspects which are closely correlated with building energy and emission [17,30]. They are: required indoor comfortable level and occupant control behavior of HVAC system; density of occupant in buildings and density of energy usage (such as lighting, hot water, appliance); and hourly schedule of occupancy and energy usage. In contrast to envelope $U$ values, lighting technologies and HVAC systems description, which could be quantitatively specified and enforced in regulations, OBs are complex, uncertain and diversified. Selecting of 
OB in building energy related regulation and standards are one of the most crucial work during the standard establishment. Naturally gap between different population (Gap 1 in Figure 3) exists, because the traditional culture and life style distinct between US, China, EU, etc.. Normally, OBs is typically simplified, standardized, or neglected in building codes, leading to Gap between real OB and OB in regulation (Gap 2 in Figure 3). As a result, $\mathrm{OB}$ description are diversified in building energy regulations (Gap 3 in Figure 3). These three kinds of gaps are extensively observed and reviewed as follow.

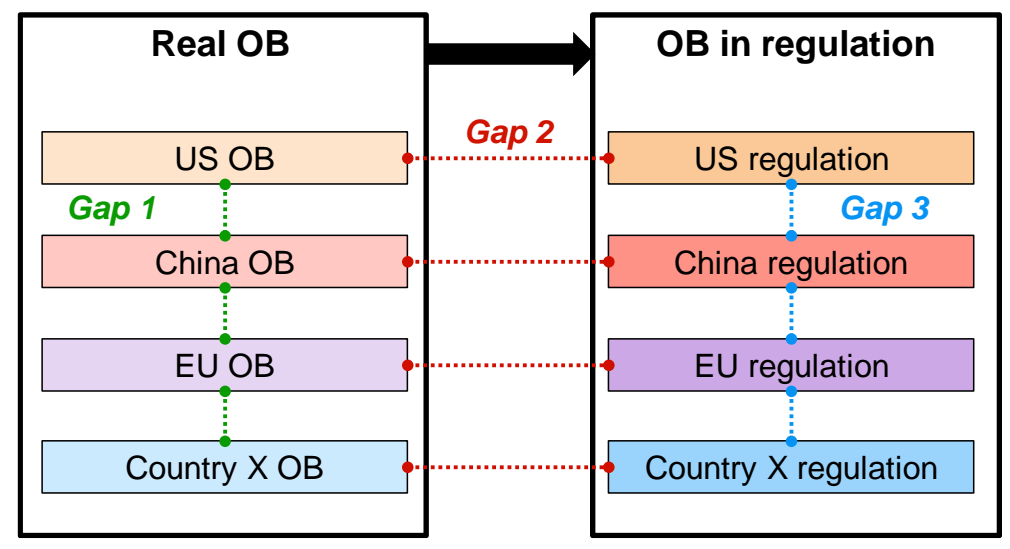

Figure 3 Gaps between real $O B$ and $O B$ in regulations

\section{a) Building design code}

Default values of $\mathrm{OB}$ and building operation status are commonly stated in building design standards, such as operating schedules, indoor temperature settings, air exchange rate, and HVAC system strategy. However, data from real building monitoring and building energy modelling indicates that the default values from building design code are not always consistent with real situation, sometimes resulting in a major gap between the two. For instance, China's design standards for energy efficiency of public buildings [31-33] is widely used to regulate the energy efficiency of physical assets (envelope, lighting, HVAC) in buildings during design stages. Figure 4 [21] shows the result of a comparison among calculated EUI (energy use intensity) according to different assumptions. The default OB is set according to technical prescriptions of OB in China's Design Standard for Energy Efficiency of Public Buildings[31]. The new assumption of OB is obtained from on-site survey and monitoring of several buildings and occupants. The EUI simulation result using default OB is much higher than EUI result with new assumptions. Actually, the default assumptions of OB in Chinese design standard were mostly borrowed from the U.S. ASHRAE Standard 90.1[34] and do not represent actual OB in Chinese buildings. The gaps between OB settings in design standard and real buildings also exist in residential buildings. The full time full space method is used in China's design standard for residential buildings [35], which assumes the internal heat gains from occupant and appliances to be constant and not changing over time nor space, in addition to the air conditioning system operating 24 hours for the seven days of the week and for all rooms. Whereas, large scale survey[15] and monitored case study[36], indicates that part time part space mode is the predominant heating behavior in hot summer and cold winter zone of China, instead of full time full space mode. Research based on questionnaire survey and monitoring data [35] indicates that a great gap 
exists between full time full space settings with real OB. Building load with full time full space method is much higher than real energy consumption, potentially lead wrong misinformed decisions on building design optimization and system choice.

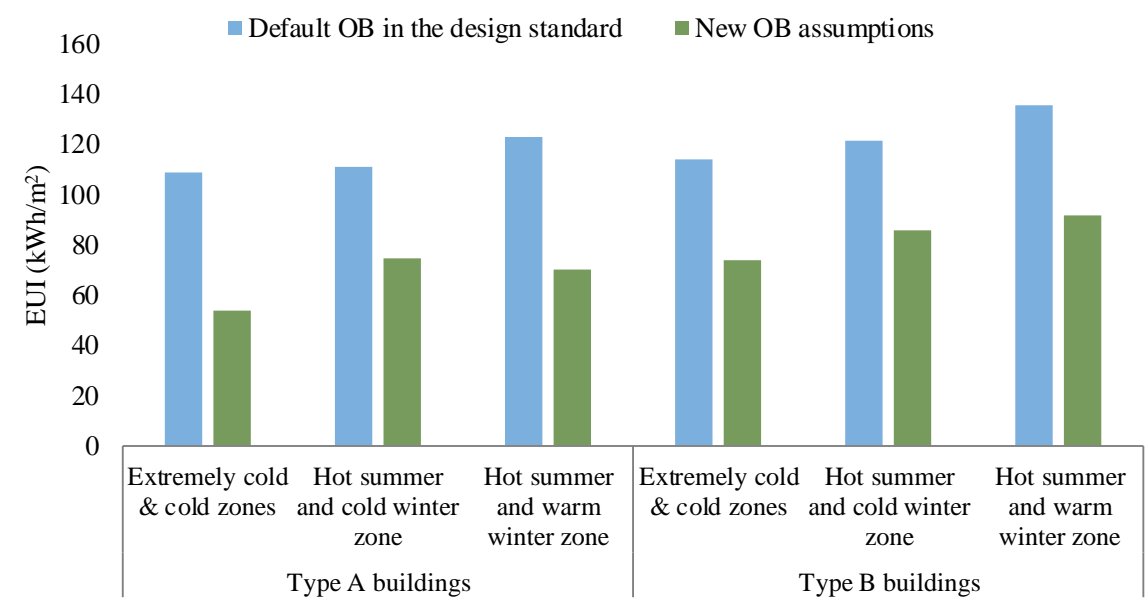

Figure 4 Comparison of EUI indicators of two public buildings under different OB assumptions[21]

Investing in building energy-efficient technologies needs to be evaluated with cost-effective analysis, either from economic perspective or from energy usage perspective. In practice, different settings of OB would lead to different building heating and cooling demands features, and finally lead to distinct choice on energy efficiency technological choice. Considering life-cycle primary energy consumption including building construction and operation, the payback time of insulation material to improve building performance level is different under different OB patterns. For instance, in a simulation according to full time full space method[37], a $20 \mathrm{~mm}$ insulation is the optimum thickness when occupants hold a "full time full space" heating pattern, while $10 \mathrm{~mm}$ is the optimal choice when OB assumptions followed a part time part space OB approach. Therefore, the choice of $\mathrm{OB}$ representation to adopt in regional building design codes is an essential factor for a successful building envelope design.

\section{b) Building system design and operation standard}

Occupancy pattern is the key input in the analysis of building demand during the design stages of buildings as it is closely related with the time of use of building service systems including HVAC, domestic hot water (DHW), lighting and appliances. Culture differences may lead to unique occupancy patterns even for buildings with similar functions, which can eventually lead to different building design code settings related to occupancy. Every day at about 12:00 (noon) in Japan, electricity demand falls more than 6GW and then returns to the prelunch trend at 13:00 [38]. This phenomenon appears because the Japanese lunch hour is strongly concentrated between 12:00 and 13:00, where Japanese office workers traditionally switch off lights, equipment and sometimes even air conditioning before leaving their workspace. However, this phenomenon does not appear in major North American or European load shapes due to different office occupancy and appliance use behaviors. 
Different occupancy and energy usage patterns lead to different electrical load profiles, requiring different building system designs and operation modes.

Not only time-of-use is distinct among different population groups, the use level is also a significant index of OB in building service systems. A typical case is DHW usage volume, which is the most important parameter for centralized DHW system design. The Chinese standard employs 143-286 liters per household per day for urban residential building as reference usage amount [39]. Centralized DHW system designed according to this assumption actually performs badly at an efficiency in the range of $29 \%-56 \%$. Actually, the current hot water consumption in urban China is only 20-80 liters per household per day, which is much lower than other countries; the average daily consumption of DHW is 280 liters per household in US [40], 200 liters per household in Spain[41], and 236-354 liters per household in Japan[42].

\section{c) Equipment/appliance standard}

$\mathrm{OB}$ is also significant setting in equipment performance regulations, especially when assumptions of $\mathrm{OB}$ are directly related with the performance evaluation indicator. For instance, variable refrigerant flow (VRF) systems became popular among Chinese high-income urban households during last decades. This lead to obvious cooling energy consumption growth and posed great challenge for China's energy conservation and emission reduction in building sector. MEPS (Minimum energy performance standard) to evaluation and regulate energy performance of VRF systems is one of the most important policy measure. Globally, several countries established their own MEPS for VRF units, such as: Chinese standard GB/T18837[43], Japanese standard JRA4048[44], American standard ANSI/AHRI1230[44], EU standard EN14511:2018[45], and international standard ISO 15042:2017[46]. These standard present requirements of testing and rating VRF units. In Chinese $\mathrm{GB} / \mathrm{T} 18837$, an annual performance factor (APF) is employed as the evaluation index to assess the air-cooled VRF system, which is defined by the combination of tested performance under three cooling conditions and four heating conditions. In these standards, the number of part-load conditions tested needs to be limited because of high experimental costs. However, real VRF operation dataset from 344 samples illustrate that low partial load ratio operation less than $30 \%$ is the most common status in Chines households due to the specific cooling $\mathrm{OB}$ [47]. Improper evaluation index mainly considering full load condition would lead to equipment designed to have best performance under full load condition (designed $\mathrm{OB}$ ), leading to suboptimal performance under partial load conditions (real OB). The COP (Coefficient Of Performance) of VRF is generally higher than singlesplit air conditioners under rated conditions, but the actual measured COP of VRF units is less than 3, which is lower than single-split ACs, due to frequent operation at loads below $25 \%[48,49]$.

\subsection{Discussion}

Building and mechanical systems serve people who live and work in the building's premises. People's demand and behavior when using those services are an important hypothesis for their optimal design and operation strategies. In reality, great challenges exist in the choice of representative OB due to both the homogeneity and heterogeneity that is observed in OB. Energy efficiency and energy consumption gaps commonly occur between 
expectation and actual situations when OB is represented improperly (i.e., when the assumption of OB differs from $\mathrm{OB}$ in the real world). In contrast, a proper OB selection close to reality typically leads to suitable building envelope and optimized systems' performances.

Various gaps of $\mathrm{OB}$ representation in building energy regulation, building design code and equipment performance standard are widely observed by the reviews. These gaps are more and more understood and highlighted by various stakeholders such as engineers, researchers and policy makers [2]. That is why OB research is gaining more frequent attention during the revision of existing building standards. Compared with prescriptive building codes and standards, performance-based building regulations has been popular due to advanced OB settings and flexibility during implementation process[50,51]. For examples, Hong Kong released performance-based building code in 2007[52], and require the overall energy performance should be better than an equivalent building.

Misunderstanding and unrealistic assumptions were made in previous technical standard due to limited availability and access to real $\mathrm{OB}$ data. To fill the gaps of $\mathrm{OB}$ in technical standards, the gathering of large-scale OB datasets and the selection of the appropriate scientific tools and methods for analysis are critical. Fortunately, more data on $\mathrm{OB}$ is becoming available and accessible, gathered through various data collection methods including questionnaires, building sensors, wearable devices, to name a few. Improvements in building technical standards and regulations can be expected soon given the great challenges facing the building sector on the energy and emission levels.

\section{Occupant behavior in building energy information tools}

\subsection{Aim and scope}

Following the review of $\mathrm{OB}$ in regulation mechanisms and standards, this section explores the role that information can play to improve the cognition of $\mathrm{OB}$ and potentially influence or alter behavior. The study of the relationship between information and action of people is not recent. Early models of human behavior, such as the "information deficit" model in the 1970s, argue that behaviors such energy conservation actions are directly linked and triggered by the knowledge of people to take such actions[53]. An important limitation of such a model is the assumption of rationality in behavior, which was later challenged with a growing body of evidence on additional drivers of behaviors such as contextual factors and differences between individuals. Numerous models emerged in the years that followed to capture a higher level of complexity in behavior. For instance, the theory of planned behavior[54] argues that attitudes, norms, and the perceived level of control over behaviors combine to determine intentions towards a behavior, which in turn determine whether a behavior is adopted or not. The Value-Belief-Norm (VBN) model builds on the previous ones, introducing an individual's beliefs as determinants of intentions, which in turn drive behaviors via norms [55]. Other models cover additional aspects such as social aspects[56], opportunities and abilities [57], among others. All models build on multifaceted drivers of people behavior, which can be organized in three distinct categories [58]: (i) 
motivational factors (e.g., knowledge, moral and normative concerns, and affect); (ii) contextual factors (e.g., physical infrastructure and control level); and (iii) habitual behavior (e.g., automated cognitive processes rather than reasoned actions).

In parallel to studies on drivers of behaviors, researchers devised and deployed strategies or interventions that can alter existing behaviors, such as OB in buildings. Broadly, interventions can be categorized in two main families: "informational" interventions (i.e., strategies that aim to change knowledge, perceptions, motivations, and norms) and "structural" interventions (i.e., strategies that aim to change the context, such as availability and costs of a behavior, of current or alternative) [57-59]. The focus of this section is on the former, as detailed next.

\subsection{Importance}

There is a large and growing body of evidence on the role of "Informational" strategies to effect human behavior. Among the three categories of behavioral drivers discussed above (motivational factors, contextual factors, and habitual behaviors), informational interventions typically target the motivational factors that affect or drive behaviors such as $\mathrm{OB}$ in buildings through various mechanisms [58]. One such mechanism is through increasing the knowledge, cognition, or awareness of people (e.g., building occupants) of their current actions or of alterative actions that they can adopt, such as energy curtailment practices[59]. Another goal of informational strategies can be persuasion-orientated, where information is used to reinforce values (e.g., altruism and ecological conservation) to induce occupants to adopt pro-environmental behaviors [60]. Lastly, social norms can be leveraged to induce behavior change by providing occupants with information about the behavior of others. Information can be provided through various media, including paper, screens, or people with behaviors that are considered desirable (role modeling and peer-pressure) [61].

In practice, various informational tools have been developed and applied in the building sector to induce changes in current OB practices. The upcoming sub-section details those instruments, followed by a discussion of their effectiveness and outlook.

\subsection{State of art}

Numerous articles, including review studies, cover intervention techniques aimed at energy consumption patterns of occupants in residential and commercial buildings [58,59,62-65]. This section synthesizes their findings, focusing on "informational" interventions targeting OB in residential and commercial buildings. A distinction is made between "antecedent" and "consequence" interventions.

\section{a) Antecedent informational interventions}

Antecedent strategies provide occupants with information that can influence one or more determinants behavior (e.g., knowledge, motivation) before the performance of the behavior. Various examples of such strategies as presented next, including education, social marketing campaigns, "role" modeling, labeling, and certifications. Education (e.g., workshops, training, and audits) is a common approach used in buildings to provide occupants with information about their interactions with their built environments, and the consequences of such actions (e.g., energy-related or ecological). The level of information can be broad, such as to promote general pro- 
environmental behaviors, or specific, targeting a specific desirable action in the building space (e.g., using HVAC set back temperature settings) [59]. Examples exist from the early 1980s on workshops conducted in buildings to provide general information about energy-savings measures [60], as well as focused home audits [66]. The latter has shown promising results with energy savings ranging from $1 \%$ to $21 \%$ in extreme cases[59,66].

Social marketing is another informational strategy defined by Kotler et al. [67], as "the use of marketing principles and techniques to influence a target audience to voluntarily accept, reject, modify, or abandon a behavior for the benefit of individuals, groups, or society as a whole". A good example of social marketing in the context of the current paper is the "Ecoteams" program established internationally as part of the Global Action Plan for the Earth to reduce household resource consumption. The 3-year longitudinal evaluation of the program confirms its effectiveness as alternating consumption patterns, with savings ranging from 7 percent for water and electricity consumption to 32 percent for solid waste deposition[68].

. Earlier examples can be found in the literature, such as the Low Cost/No Cost energy conservation program of the US Department of Energy. The program started in 1979 and sent energy conservation tips using booklets to 4.5 million households. The results confirmed the effectiveness of the program as 29 percent of the households reported the installation of water flow controllers, 19 percent made furnace efficiency modifications, and 16 percent checked for gaps in their fireplaces[69]

"Role" modeling is a strategy that consists of providing occupants with examples of recommended or ideal behaviors, with the assumption that people will follow such behaviors if well understood and relevant to them. Such a strategy is often coupled or integrated with other methods (e.g., training and marketing campaigns). An early example is found in Winett et al. [66] who reported on a modeling program communicated to homeowners via TV cable. The targeted households reduced energy consumption by $10 \%$ compared to a control group. Staddon et al. [62] report on more recent studies that applied modeling differently, through the profiling or employees who embody good (or "role") pro-environmental behaviors. Here again, modeling was integrated into large-scale behavioral changes programs, achieving relatively high energy saving levels, such as 2 percent in Owen et al. [70], 9 percent in Gustafson et al.[71], and 5.4 percent in Hargreaves [72]

Finally, it is worth noting that occupants might receive information through indirect channels such as green product labeling or and green building rating certifications such as LEED. Such mechanisms might contribute to raising the awareness of occupants towards energy conservation, which might result in favorable OB patterns. Conversely, an unintended consequence might arise where the increase in the energy efficiency of a technology/system results in an increase in consumption by the user, given the reduced cost (financial, social, or psychological) of using that system. This phenomenon is commonly referred to as the "rebound effect'[72][73].

\section{b) Consequence informational interventions}

Consequence interventions provide occupants with information following the performance of the behavior. The primary method relevant to this section is energy feedback, which consists of providing occupants with 
information about their energy consumption patterns to positively influence those patterns. It is argued that feedback is an effective behavioral change mechanism as it highlights the relationship between an energy-related action and its result (e.g., change in energy use level), promoting a form or outcome expectancy or belief that behavior leads to a desirable outcome[74].

An early example of a successful feedback mechanism is found in Seligman and Darley [75], where the authors provided households with feedback on their consumption from the previous day over a one-month period. The households that received feedback and educational information showed an additional $11 \%$ in energy savings compared to households that only received educational information. A review of more recent feedback studies confirms the potential of this method, showing energy savings often in the range of 5-15\%[59] with averages around $7 \%$ [76]. There two important variables in feedback mechanisms that are worth discussing.

The first variable is the frequency of the feedback varies significantly between the studies. Examples of different frequencies include monthly, weekly, daily, as well as continuous feedback [59]. The media for the feedback information also varies from (i) physical reports, (ii) digital reports (e.g., emails), and (iii) monitors (e.g., dashboards and displays). The latter is mainly employed for continuous feedback where occupants are provided with real-time (or recent) information about their energy consumption levels. The frequency of information can also be tightly coupled to the frequency of reporting. For instance, feedback provided with the utility bill will typically be limited to the reporting frequency of the bill (e.g., monthly). For this example, bill disclosure mechanisms are essential to maximize participation and increase the statistical significance of the feedback information provided.

The second important variable of feedback mechanisms is the nature of the information presented, whether it is "comparative" or not. Comparative feedback frames the energy consumption information received by occupants relative to the consumption levels of others. This has shown to evoke social comparison, competition, and pressure, which can be effective at inducing behavioral change. The impact of comparative feedback has been recently tested in a unique study by [77]. The authors divided the occupants of a dormitory building in three groups and provided them different types of feedback: (i) own electricity usage, (ii) own electricity usage with contextualized average building occupant utilization, and (iii) own electricity usage with contextualized average building occupant utilization and electricity usage of their peers in the building. The latter group witnessed the highest reduction in electric usage (28\%) during the intervention period. However, similar to the other groups, a relapse to pre-intervention levels was observed within few days following the experiment. In general, the results of this experiment (and other norm-driven interventions) are context dependent as people's attitudes and behaviors are typically driven by the standards of individuals (or groups) with whom they share a unit relationship [78]. Therefore, their results cannot be necessary generalized to other buildings with different social group characteristics.

\subsection{Discussion}

Based on the results of multiple studies on occupancy interventions $[58,59,64,65,79-81]$, it can be concluded that informational interventions have a significant potential to affect determinants of OB in buildings. This 
observation is in line with the work of Delmas et al.[82], who performed a statistical analysis on the results of 156 published articles on informational interventions. The authors observed that despite large variations in the results of the studies, the average electricity consumption is positive and estimated at 7.4 percent. Nonetheless, the literature reviewed in the current section highlights important limitations in the experimental designs that are followed, which calls for further investigation and research on the topic.

Firstly, as mentioned above, the effectiveness of the interventions varies significantly between the studies, making the real impact of the interventions on $\mathrm{OB}$ and energy consumption unclear. The variation in results is found between, as well as within specific methods.

Secondly, in the vast majority of the case studies, the long-term effects of the interventions were not measured. Consequently, it is unclear whether the promoted behaviors by the interventions are sustained after the end of the intervention periods and for how long.

Thirdly, informational strategies seem to be particularly effective when the promoted behaviors are (i) convenient, (i) not very costly in terms of time, effort, and social disapproval, and (iii) not hindered by physical constraints such as access to a particular control. The above constraints require researchers to often combine informational strategies with other techniques such as rewards or structural changes, which further complicates the effort to isolate and validate its effect on OB. Future research efforts are needed to address the above limitations and reduce the ambiguity about the actual effectiveness of information strategies at inducing substantial and sustained behavioral changes. Such a step is essential to increase the confidence of building policymakers in this human-focused approach to energy conservation and deploy it in current and future energy policy tools and strategies.

\section{Occupant behavior in building energy incentives}

\subsection{Aim and scope}

In many cases, behavior change programs based on communication and instruments may not always be adequate, various incentives maybe then required [83]. The aim of OB intervention by incentives is using economic incentives, either positive or negative, to shift the distribution of $\mathrm{OB}$ from an energy intensive direction to a less intensive, and to motivate occupants change or adjust their energy related behavior inside buildings from individual perspective.

\subsection{Importance}

Besides regulation, information tools, analysis on global best-practice building policies shows that world's best performance based regulations are being designed and practiced with incentives, which is "carrots", to encourage and stimulate innovation rather than simply punish poor performance[84]. High capital costs is among the top barriers for the adoption of building energy efficiency measures[85]. Individuals are usually lack of professional knowledge and scientific judgment on new building energy efficiency technologies. To them, financial incentives nudge them to make more aggressive choice. Numerous evidences indicate that economic 
incentives raises the homeowners' likelihood of purchasing energy efficient household appliances in Denmark[86], replacing heating system in Italy families[87], and adoption of renewable energy products in US home[85].

To organizations in public buildings, marginal cost of building energy efficiency is one of the biggest obstacles for both new-constructed buildings and existing buildings. High implicit discount rates, undervaluation and uncertainty of future energy and cost savings, and negative cost energy efficiency measures have all been discussed as barriers of building energy efficiency and causes of "energy efficiency gap" [88]. Financial incentives that help industries and business to reduce the manufacture costs may also promote building energy efficiency[85]. On the other hand, from society level, incentives encourage potential technical innovation by reduce initial cost of new technology and overcome resistance to new technology due to high initial price.

\subsection{State of art}

Generally, two types of building energy related decision behaviors were considered in building energy behavior related the incentives: first is investment decision of building users, including minor investment decisions such as choosing more efficient home appliances by individual household and major change such as putting building insulation material outside of building by organizations; the other one is life style and energy usage habits and patterns, minor behavior change such as changing time of using dish-washer is easier, major behavior change such as changing one's life style is much harder with high social and economic cost.

\section{a) Investment behavior related building energy incentives}

Investment behavior is typically evaluated by the theory of planned behavior, which assumes that consumers weigh their options in terms of costs and benefits before picking the most cost-effective one[89,90]. Improving building energy performance through purchasing more energy-efficient equipment usually involves higher first costs, which many building consumers may not want to spend or simply cannot afford (e.g., low-income consumers). Targeting investment behaviors that promote building energy efficiency, financial incentives were usually provided through policy instruments to enlarge the benefit and decrease the cost barriers of adoption. For organizations and public buildings, government procurement regulations with provision for energy efficient equipment's are mainly used. This is considered as one of the most effective instruments due to the large share of public building energy consumption and high policy implementation rates. For instance, the largest U.S. energy consumer is the federal government with more than 350,000 buildings, totaling more than 2.7 billion square feet [91]. The US, with its Federal Energy Management Program (FEMP), has one of the most stringent legislative framework for public procurement. For instance, US federal agencies are required by the Energy Policy Act of 2005, Executive Order 13123 to purchase ENERGY STAR-qualified or FEMP designated products as well as to purchase producing using less power in the standby mode. The energy performance requirement for Federal buildings required that each Federal agency must reduce the energy consumption per gross square foot of its buildings by $30 \%$ in 2015, relative to fiscal year 2003 that was used as baseline [92]. Germany, France and Italy have also introduced environmental and energy efficiency specifications into public procurement regulations while the UK procurement law even demanded life-cycle cost-assessment [93]. 
In residential buildings, subsidies are commonly used to encourage the adoption of energy-efficient building systems and technologies that contribute towards higher-performing buildings. For instance, numerous countries such as Poland, Thailand, Mexico, Jamaica, Peru, Brazil, Demark and the United Kingdom adopted energy efficient lighting programs since the 1990s [94]. China's Ministry of Finance (MOF) and the National development and reform commission (NDRC) initiated a subsidy program targeting efficient air-conditioners and lighting bulbs in 2009 and these subsidies were later introduced for five other home appliances in 2012 [95]. The Japanese government ran the ECO-Point system from 2009 to 2011 for the purchase of air conditioners, refrigerators, and televisions that were rated four or more stars by the national energy-efficiency standard and labeling program [96]. This program led to significant increases in the adoption of energy efficient products and was considered very successful; it is estimated that the share of products with four stars or more increased from $20 \%$ to $96 \%$ for air conditioners, from $30 \%$ to $98 \%$ for refrigerators, and from about $84 \%$ to $99 \%$ for televisions. In summary, targeting specific products and users, coupled with simple implementation processes, are key factors for effective economic incentives targeting occupants' purchasing behaviors of energy efficient equipment. In addition, involving appropriate expertise across a range of disciplines is critical during the design stage of these policies to ensure a maximal adoption of the promoted building solutions [63].

\section{b) Habitual behavior related building energy incentives}

Habitual behavior represents an action taking by a person repeatedly and automatically without weighing up its pros and cons [63]. Most energy related behaviors are habitual in nature, making them difficult to alter unless a change in the external circumstances occur to "break" the habit loop. In the building sector context, economic incentives are commonly provided to encourage two types of habitual behavior change: decreasing energy use through conservative actions or switching the time of use of specific building systems. Energy pricing schemes with tiered pricing or peak valley pricing are among the most common and successful fiscal incentives to encourage more efficient energy demand patterns than currently adopted ones.

Tiered electricity price, also referred to as TCP, divides electricity consumption into several blocks and charges higher prices for electricity in the higher blocks [97]. Compared with sampling raising energy price, TCP could prevent energy poverty of low-income families, which are proved to have smaller elasticity of energy consumption, and guarantee the basic energy usage[98]. Implementing TCP in the residential building sector is conducive to improving the equity and efficiency, and thereby promoting electricity conservation and energyrelated emissions reduction[99]. For example, TCP implemented across China from 2012 helped households change alter inefficient patterns of electricity consumption[98,100]. Implementing TCP in public buildings could raising public awareness on energy saving, influence occupants energy usage pattern in terms of lighting, computer and other appliances, and reduce building energy use obviously[101].

Peak and valley electricity scheme is another useful tool that consists of increasing energy prices during onpeak periods, effectively decreasing on-peak power and distributing parts of it to off-peak hours. Studies confirm this effect and show that the higher the increase in on-peak tariffs, the more obvious the load curtailment and shifting are [102]. Such scheme can also promote consumers' investment in renewable sources of energy. For 
instance, California adopted TCP and Time-Of-Use Net Metering [103] while providing subsidies for solar power systems. This resulted in attractive financial paybacks on solar panels, promoting their wide adoption in the residential building sector [104].

In summary, the above strategies are often presented as promising demand side management strategies that can reduce peak demands and improve the efficiency of matching the supply and demand sides of the power grid [105]. Time-varying electricity pricing is a key strategy used by electric utilities to incentivize private consumers to change their current, often habitual, electric consumption patterns. Numerous experiences from Europe and the world confirm that intelligent control strategies associated with demand response programs can lead to significant and large-scale energy savings [106].

\subsection{Discussion}

The complexity of $\mathrm{OB}$ in buildings requires a specific focus on energy policy design, implementation and evaluation. Firstly, energy efficiency measures can sometimes lead unintended consumption increase, which is the phenomenon referred to as the "Jevon's paradox" or latterly defined as "rebound effect" [73,107]. For instance, district cooling systems with renewable energy utilization (such as ground source heat pump) get allowances from the Chinese government. It has been observed that the consumers supplied by such "green" system consume more electricity compared to users supplied by conventional systems of energy generation [108]. Similarly, in Shanghai, China, homes with installed building insulation achieved higher temperatures in winter (i.e., improved thermal comfort) but on the other hand consumed more electricity compared to families without insulation [37].

Secondly, as stakeholders in the building energy sector are normally diverse and scattered, the benefits and costs of energy saving investments do not always affect and benefit the same stakeholders. In cases where purchaser who pays additional cost by adopting energy efficiency products but they are not actual users who could experience benefits of reduce energy consumption and cost, "principal-agent" problems may be caused and lead to failure of policies [109].

Finally, there are generally more than one energy-consumer in a typical building, which can easily cause "freeride" effect. This could become an obstacle for investing in energy saving measures such as building envelope insulation measures, which require the cooperation and contribution of all users. The "free ride" effect is also notable for space heating service where apartment building households will spend more energy for space heating during winter if their neighbors do not heat their spaces. This increase in heat loads compensates for the increase in heat losses through internal walls. In Norway, it was estimated that $70 \%$ of the participants in a program providing subsidies for energy efficiency investments were "free riders" [110]. Such phenomenon should be well studied and accounted for in the design of energy policies to ensure effective results and mitigate unintended consequences on $\mathrm{OB}$ and building performance [111]. 


\section{Challenge and opportunity}

\subsection{Challenges}

The proceeding sections have shown the significance of $\mathrm{OB}$ in BEP and that obvious progress has recently been made towards the development of OB cognition in BEP. However, barriers still exist during the whole process of BEP from policy development, implementation, monitoring and evaluation.

In building energy regulation policy tools, lack of recognition for real OB distribution leads to gaps between selected $\mathrm{OB}$ in regulations and real typical $\mathrm{OB}$, and causes problems of code and standard implementation. Inaccurate building simulation and the optimization according to deviated OB settings may cause unsuitable technology adoption and investment on building energy efficiency. Large scale of OB data collection, identification and application analysis is useful to fill the gap, namely reduce the cognition deviation and improve OB definition in BEP, as shown in Figure a.

In building information measures, monitoring and evaluation policy effect are most difficult due stochastic nature and diversity of $\mathrm{OB}$. Better design of information tools could be achieved if they are designed according to a scientific understanding of $\mathrm{OB}$, convenient implementation method, and with low cost of time, effort and social approval.

Furthermore, building financial incentives could effectively increase the benefit of energy policy investment and energy conservation behaviors, but heedless BEP design would cause "rebound effect" due to uncertainty of building service from distinct occupant. There are also implementation risks such as "principal-agent" problems" and "free-ride" effect because multiple stakeholders exist in the building energy sector.

Digging up the nature and drivers of $\mathrm{OB}$ in population, defining specific targeted intervention BEP would effectively change OB distribution in population, and decrease share of energy intensive OB as shown in Figure b.

Table 1 Key research issues of $O B$ in BEP

\begin{tabular}{l|l|l|l}
\hline BEP process & Regulation & Information & Incentives \\
\hline Development & $\mathrm{X}$ & & $\mathrm{X}$ \\
\hline Implementation & $\mathrm{X}$ & & $\mathrm{X}$ \\
\hline Monitoring & & $\mathrm{X}$ & \\
\hline Evaluation & & $\mathrm{X}$ & \\
\hline
\end{tabular}




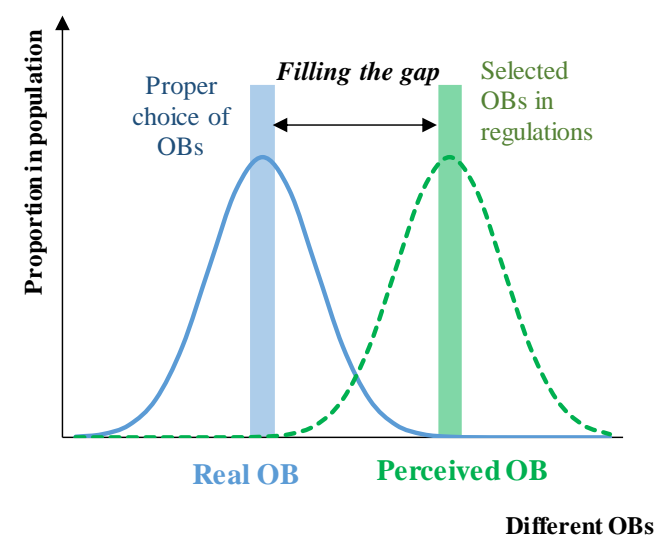

a) Filling gap of OB definition in BEP

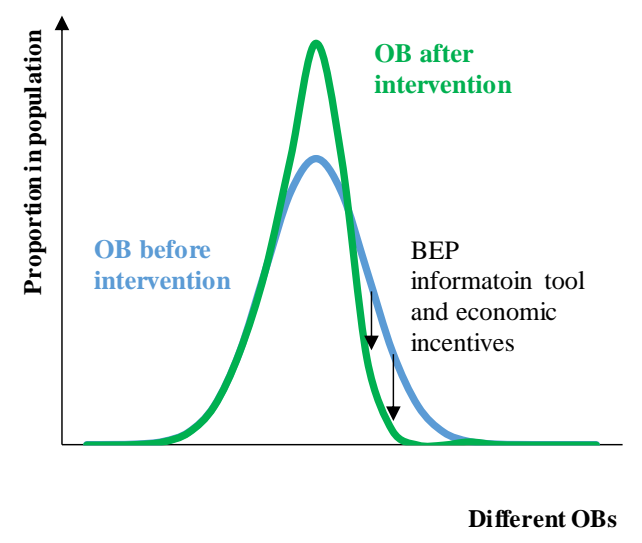

b) Intervention on $\mathrm{OB}$ with proper BEP

Figure 5 Conceptual illustration of OB research barriers in BEP

General challenges across the mentioned BEP in the literature on OB include the difficulty in OB data collection, the cross-disciplinary nature of $\mathrm{OB}$, and the uncertainty in the evaluation metrics for $\mathrm{OB}$ related BEP.

\section{OB data and sharing protocol deficiency}

Data sufficiency is the biggest challenge for understanding the nature, diversity and distribution of OB[2,7,112] Collection of OB data is normally high in cost and hard to implement[113-115], because of high capita cost of occupancy sensors (including occupancy sensors, indoor environment sensors, and occupant behavior sensors such as appliance sensors)[116]. OB in building appliance operation such as AC or television is easier because the monitoring of appliance energy usage would reflect OB directly. On the other hand, the detection of behavior with the building itself is harder, such as real time occupancy at room level with occupancy sensors, opening of windows by action sensors, or controlling shading devices by camera or actions sensors. Due to privacy issues, the data sharing protocol absence also causes barriers for research institutions and researches to share OB dataset easily and establish cross-sectoral collaborative research.

\section{OB coupling with other factors and cross-disciplinary nature}

The cross-disciplinary nature of $\mathrm{OB}$ and coupling of $\mathrm{OB}$ with buildings, technologies, and other social-economic factors introduce further difficulties[7,117]. The coupling of OB with building envelope, system and terminals make it harder to choose proper service system, bringing policy makers and engineers more difficulty on technological policy choice[10,118,119]. Unsuitable choice of OB related BEP would sometimes, either promote building demand and achieve high energy consumption due to limitation of system, or cause energy poverty and bring more unfairness on the energy usage sector. The cross-disciplinary nature of the problem requires scientific understanding of $\mathrm{OB}$ from the sociology, psychology, economic, ethics, and engineering perspectives.

\section{OB uncertainty and unpredictable in BEP assessment}

Occupant behaviors are influenced by various interweaved factors, such as income, gender, age, educational 
level, socio-cultural background, awareness and attitudes towards energy issues, perception of indoor thermal quality as well as outdoor temperature [120]. In consequence, occupant behaviors are truly in a wide range with certain distribution, full of uncertainty from the individual level, and hard to predict from the population level [121]. In BEP assessment, OB is often integrated into the simulation environment as a set of fixed assumed or pre-defined schedules $[117,122,123]$, while its distribution is often ignored and rarely taken into consideration in the simulation [117]. There are several reasons for this shortcoming: 1) occupant behaviors are quite diverse and collecting relevant large-scale data requires significant efforts in terms of human and financial resources; 2 ) there exist certain knowledge/technical barriers for modelers to model occupant behaviors, for example, methodologies to untie interweaved occupant behaviors, theories or methods to quantitatively model occupant behaviors, etc.; and 3) compared to examining the correlation of occupant behaviors with their internal drivers (e.g., habits and preferences), it is much more convenient to establish the correlation of occupant behaviors with some external explanatory variables (e.g., outdoor weather) because of the ease of collecting the relevant data [121,124-126]. The simplified assumption of occupant behaviors in building energy simulation is often considered as one of the main reasons for the gap between projected and actual energy performance of buildings, also called building energy performance gap [120,127]. Inaccurate simulation undermined the reliability of policy assessment. Additionally, without reflecting the wide distribution or heterogeneities of occupant behaviors into policy assessment, it remains challenging for policymakers to examine the impacts of incentive polices on the dynamics of occupant behaviors, an important step for an accurate projection of future energy use in the building sector.

\subsection{Opportunities}

\section{Big data collection from ICT and 5G technology}

Thanks to the advances and application of real-time monitoring and sensing technologies, a growing number of data mining approaches are emerging. These approaches offer a powerful technique to describe the full effects of occupancy behaviors from large-scale real energy consumption data. They utilize methods from the fields of machine learning, pattern recognition (e.g., clustering), statistics, databases and visualization, which could provide reliable information on OB patterns, schedules and distribution [128,129]. With big data collection method becoming popular and the spread of $4 \mathrm{G}$ and $5 \mathrm{G}$ technology, OB collection from ICT (intelligent consumer technology) and intelligent sensors achieved large database, bringing valuable opportunities for understanding $\mathrm{OB}$ in the areas of: a) occupant movement and presence, b) thermal comfort; c) operation of windows, shades and blinds; and d) usage of lighting and electrical equipment[117]. Advancements in data collection techniques, analytical and modeling methods, and simulation applications have provided insights into OB and energy saving potential and opportunities. Along with the availability of big data, state-of-the-art data mining and processing techniques offer a promising platform for policymakers and researchers to more accurately measure the full effects of occupancy behaviors in building energy use and policy assessment. Such a progress in $\mathrm{OB}$ understanding will help better BEP shaping, targeting, implementing and evaluating. 


\section{Building energy sufficiency instead of building energy efficiency}

Building energy efficiency policies focus on efficiency improvement is inadequate especially for emerging economies with rapid social and economic development. The "rebound effect" in the building energy sector often appeared simultaneously with the rise of building energy efficiency. To address this, policies aiming to influence consumer behavior and lifestyle with the concept of sufficiency have been introduced in the building energy policy sector $[130,131]$. Building energy policies targeting sufficiency aim at capping or discouraging rises in energy use due to increased floor space, comfort levels, and equipment ownership [131,132]. Policy instruments, such as personal carbon trading, property taxation, and progressive appliance standards and building codes with absolute energy consumption limits rather than efficiency requirement, were promoted as building sufficiency drivers. These policies focused on suitable building energy demand, encouraged diversified behaviors and lifestyles, and reduced energy consumption at a societal level. Such policies might be a new and effective approach for developing countries to mitigate building energy consumption growth and climate change challenge while raising general building living conditions [133].

\section{Outcome-oriented and data-based building energy policy}

Outcome-oriented and data-based BEP would make the policy making, monitoring and assessment easier and single target focused. Facing energy security and climate change issues, decreasing building final energy intensity is becoming the core issue and policy target for both developed and developed countries. For instance, the standard of energy consumption quotas (ECQs) for buildings with different types was established and implemented in China in 2016 [37,134]. Annual ECQs of electricity and gas were given, and a corresponding annual assessment was conducted to check the compliance uniquely according to the final building energy usage monitored data. This concept and measures provide significant guidance and reference for future BEP making for other countries[134].

\section{Conclusion}

Occupant behavior is one of the major factors of uncertainty in building energy usage prediction, causing inaccuracies in building energy consumption analyses. The lack of understanding on the stochastic, diversity and inter-disciplinary nature of occupant behavior causes problems in building energy polices' development, implementation, monitoring and evaluation. This paper highlighted the research needs of properly integrating OB in building energy polices by reviewing the state of the art OB research in BEP, identifying and discussing key challenges facing the research community on the topic. General review conclusions are:

Default OB assumptions exist in building energy regulation and often cause unsuitable choice of building envelope, technologies, system design and operation. A better understanding of real occupancy patterns and behaviors would fill the gap between proper choice (close to real $\mathrm{OB}$ ) and current choices (deviated from real $\mathrm{OB})$ in BEP.

Building information tools and intervention tools vary significantly depending on the targeted occupant groups, 
detailed policy measures, and the constraint of implementation. The presence of multiple stakeholders, uncertain service levels and diversity of OB cause uncertainties in BEP design, implementation and final effects.

OB data collection evolution and data mining algorithm development, new BEP concepts such as energy sufficiency, and outcome-oriented policy tools pave the way for better and more effective BEP development. There has been growing interests, research and applications in this field, but significant challenges and opportunities still lie ahead.

\section{Acknowledgements}

This study was supported by the Youth Program of National Natural Science Foundation of China (Grant No. 51908311), China Postdoctoral Science Foundation (Grant No. 2019M660654), and National Natural Science Foundation of China (Grant No. 51778321). The authors recognize the inspiration for this paper obtained from participation in IEA EBC Annex 79.

\section{References}

[1] International Energy Agency/Organisation for Economic Co-operation and Development, Global Alliance for Buildings and Construction, 2018 Global Status Report, (2018) 325. http://www.ren21.net/wp-content/uploads/2018/06/17-8652_GSR2018_FullReport_web_final_.pdf.

[2] T. Hong, D. Yan, S. D'Oca, C. Chen, Ten questions concerning occupant behavior in buildings: The big picture, Build. Environ. 114 (2017) 518-530. doi:10.1016/j.buildenv.2016.12.006.

[3] Peter Graham, 'Bats' - not 'Sticks': Building Energy Regulations Should Encourage Innovation, (2013). http://www.gbpn.org/our-blog/‘bats'---not-'sticks'-building-energy-regulations-shouldencourage-innovation.

[4] IEA, Toolkit: Energy efficiency policies and target setting, Paris, 2019. https://www.iea.org/training/calendar/energy-efficiency-training-week-paris-may-2019.html.

[5] I. Azevedo, E. Delarue, L. Meeus, Mobilizing cities towards a low-carbon future: Tambourines, carrots and sticks, Energy Policy. 61 (2013) 894-900. doi:10.1016/J.ENPOL.2013.06.065.

[6] W. O’Brien, H.B. Gunay, The contextual factors contributing to occupants' adaptive comfort behaviors in offices - A review and proposed modeling framework, Build. Environ. 77 (2014) 77-87. doi:10.1016/J.BUILDENV.2014.03.024.

[7] D. Yan, T. Hong, B. Dong, A. Mahdavi, S. D’Oca, I. Gaetani, X. Feng, IEA EBC Annex 66: Definition and simulation of occupant behavior in buildings, Energy Build. 156 (2017) 258-270. doi:10.1016/j.enbuild.2017.09.084.

[8] P. Hoes, J.L.M. Hensen, M.G.L.C. Loomans, B. de Vries, D. Bourgeois, User behavior in whole building simulation, Energy Build. 41 (2009) 295-302. doi:10.1016/j.enbuild.2008.09.008.

[9] B.F. Balvedi, E. Ghisi, R. Lamberts, A review of occupant behaviour in residential buildings, Energy 
Build. 174 (2018) 495-505. doi:10.1016/j.enbuild.2018.06.049.

[10] T. Buso, V. Fabi, R.K. Andersen, S.P. Corgnati, Occupant behaviour and robustness of building design, Build. Environ. 94 (2015) 694-703. doi:10.1016/j.buildenv.2015.11.003.

[11] IEA, Global Status Report for Buildings and Construction 2019, 2019. doi:10.1038/s41370-017-00149.

[12] M.A. Halverson, B. Shui, M. Evans, Country Report on Building Energy Codes in the United States, (2009). doi:10.2172/978981.

[13] M. Evans, V. Roshchanka, P. Graham, An international survey of building energy codes and their implementation, J. Clean. Prod. 158 (2017) 382-389. doi:10.1016/J.JCLEPRO.2017.01.007.

[14] O.G. Santin, Behavioural Patterns and User Profiles related to energy consumption for heating, Energy Build. 43 (2011) 2662-2672. doi:10.1016/j.enbuild.2011.06.024.

[15] S. Hu, D. Yan, S. Guo, Y. Cui, B. Dong, A survey on energy consumption and energy usage behavior of households and residential building in urban China, Energy Build. 148 (2017) 366-378. doi:10.1016/j.enbuild.2017.03.064.

[16] X. Feng, D. Yan, C. Wang, H. Sun, A preliminary research on the derivation of typical occupant behavior based on large-scale questionnaire surveys, Energy Build. 117 (2016) 332-340. doi:10.1016/j.enbuild.2015.09.055.

[17] E. Delzendeh, S. Wu, A. Lee, Y. Zhou, The impact of occupants' behaviours on building energy analysis: A research review, Renew. Sustain. Energy Rev. 80 (2017) 1061-1071. doi:10.1016/j.rser.2017.05.264.

[18] M.J. Pelenur, H.J. Cruickshank, Closing the Energy Efficiency Gap: A study linking demographics with barriers to adopting energy efficiency measures in the home, Energy. 47 (2012) 348-357. doi:10.1016/j.energy.2012.09.058.

[19] P. De Wilde, The gap between predicted and measured energy performance of buildings: A framework for investigation, Autom. Constr. 41 (2014) 40-49. doi:10.1016/J.AUTCON.2014.02.009.

[20] P. van den Brom, A. Meijer, H. Visscher, Actual energy saving effects of thermal renovations in dwellings-longitudinal data analysis including building and occupant characteristics, Energy Build. 182 (2019) 251-263. doi:10.1016/j.enbuild.2018.10.025.

[21] D. Yan, T. Hong, C. Li, Q. Zhang, J. An, S. Hu, A thorough assessment of China's standard for energy consumption of buildings, Energy Build. 143 (2017). doi:10.1016/j.enbuild.2017.03.019.

[22] N. DellaValle, A. Bisello, J. Balest, In search of behavioural and social levers for effective social housing retrofit programs, Energy Build. 172 (2018) 517-524. doi:10.1016/j.enbuild.2018.05.002.

[23] S.J. Quan, Q. Li, G. Augenbroe, J. Brown, P.P.-J. Yang, Urban Data and Building Energy Modeling: A GIS-Based Urban Building Energy Modeling System Using the Urban-EPC Engine, Springer Berlin Heidelberg, 2015. doi:10.1007/978-3-319-18368-8_24.

[24] G. Dermentzis, J. Schnieders, R. Pfluger, D. Pfeifer, W. Feist, F. Ochs, An overview of energy district tools in Europe and the importance of an equivalent heating reference temperature for district 
simulations, Bauphysik. 39 (2017) 279-334. doi:10.1002/bapi.201710036.

[25] G. Killip, T. Fawcett, K.B. Janda, Innovation in low-energy residential renovation: UK and France, Proc. Inst. Civ. Eng. 167 (2014) 117-124. doi:10.1680/ener.14.00011.

[26] N. Murtagh, B. Gatersleben, C. Fife-Schaw, Occupants' motivation to protect residential building stock from climate-related overheating: A study in southern England, J. Clean. Prod. 226 (2019) 186194. doi:10.1016/j.jclepro.2019.04.080.

[27] R. Niemierko, J. Toeppel, T. Traenkler, A D-vine copula quantile regression approach for the prediction of residential heating energy consumption based on historical data, Appl. Energy. 233 (2019) 691-708. doi:10.1016/j.apenergy.2018.10.025.

[28] T. Forman, R. Mutschler, P. Guthrie, E. Soulti, B. Pickering, V. Bystrom, S.M. Lee, Improving Building Energy Performance in Universities: The Case Study of the University of Cambridge, in: Handb. Theory Pract. Sustain. Dev. High. Educ., Spinger, 2017: pp. 243-266. doi:10.1007/978-3-31947868-5_16.

[29] M. Rosenberg, R. Hart, J. Zhang, R. Athalye, Roadmap for the Future of Commercial Energy Codes, (2015). http://www.pnnl.gov/main/publications/external/technical_reports/PNNL-24009.pdf.

[30] J. Page, D. Robinson, N. Morel, J.L. Scartezzini, A generalised stochastic model for the simulation of occupant presence, Energy Build. (2008). doi:10.1016/j.enbuild.2007.01.018.

[31] China Ministry of Housing and Urban-Rural Development, DesignStandard for Energy Efficiency of Public Buildings GB50189, Ministry ofHousing and Urban-rural Development, Beijing, 2015.

[32] China Ministry of Construction, Design Standard for Energy Efficiencyof Public Buildings GB501892005, China Architecture and Building Press, Beijing, 2005.

[33] China Ministry of Construction, Energy Conservation Design Standardon Building Envelope and Air Conditioning for Tourist Hotels, China Architecture and Building Press, Beijing, 1993.

[34] R. and A.-C.E. ASHRAE (American Society of Heating, ANSI/ASHRAE/IES Standard 90.1: Energy Standard for Buildings Except Low-Rise Residential Buildings, 2016.

[35] China Ministry of Housing and Urban-Rural Development, Design standard for energy efficiency of residential buildings in hot summer and cold winter zones, 2010.

[36] S. Guo, D. Yan, C. Peng, Y. Cui, X. Zhou, S. Hu, Investigation and analyses of residential heating in the HSCW climate zone of China: Status quo and key features, Build. Environ. 94 (2015). doi:10.1016/j.buildenv.2015.10.004.

[37] S. Hu, S. Guo, Going beyond policies focused on building energy efficiency technologies - evidences and lessons from China, ECEEE 2019 Summer Study. (2019) 293-302.

https://www.eceee.org/library/conference_proceedings/eceee_Summer_Studies/2019/2-whats-next-inenergy-policy/going-beyond-policies-focused-on-building-energy-efficiency-technologies-evidencesand-lessons-from-china/.

[38] A. Meier, Japan 's 6 GW lunch break, Eceee 2015. (2015) 2003-2007.

[39] L. Yonghong, Z. Shigang, Analysis of a variety of domestic hot water heating methods, Water 
Wastewater Eng. (2013) 18. doi:10.13789/j.cnki.wwe1964.2013.04.016.

[40] U.S. Energy Information Administration, Residential Energy Consumption Survey (RECS), (2015). https://www.eia.gov/consumption/residential/.

[41] V. Dorer, A. Weber, Energy and $\mathrm{CO} 2$ emissions performance assessment of residential microcogeneration systems with dynamic whole-building simulation programs, Energy Convers. Manag. 50 (2009) 648-657. doi:10.1016/J.ENCONMAN.2008.10.012.

[42] J. An, D. Yan, G. Deng, R. Yu, Survey and performance analysis of centralized domestic hot water system in China, Energy Build. 133 (2016) 321-334. doi:10.1016/j.enbuild.2016.09.043.

[43] Y. Feng, X. Zhang, Discussion on IPLV in Standard GB/T 18837-2002 Multi-connected Air-condition (Heat Pump) Unit, J. Refrig. 30 (2009) 32-35. doi:10.3969/j.issn. 0253-4339. 2009. 06. 032.(in Chinese)

[44] ASHRAE, ANSI/AHRI1230 Performance rating of variable refrigerant flow (VRF) multi- split airconditioning and heat pump equipment, 2010.

[45] Comite Europeen de Normalisation, EN 14511-2:2018 Air conditioners, liquid chilling packages and heat pumps for space heating and cooling and process chillers, with electrically driven compressors, 2018.

[46] International Organization for Standardization, ISO 15042:2017 Multiple split-system air conditioners and air-to-air heat pumps - Testing and rating for performance, 2nd ed., 2017. https://www.iso.org/standard/63408.html.

[47] H. Liu, M. Qian, D. Yan, U. Berardi, Performance of VRF systems based on large scale monitoring, IOP Conf. Ser. Mater. Sci. Eng. 609 (2019). doi:10.1088/1757-899X/609/5/052012.

[48] J. Cheng, Survey and study report on application for refrigeration and air-conditioning products in China 2018, China quality and standards publishing\&media, 2018. (in Chinese)

[49] IEA and Tsinghua University, The Future of Cooling in China sustainable air conditioning, 2019.

[50] G.C. Foliente, Developments in performance-based building codes and standards, For. Prod. J. 50 (2000) 12.

[51] B. Meacham, R. Bowen, J. Traw, A. Moore, Performance-based building regulation: current situation and future needs, Build. Res. Inf. 33 (2005) 91-106.

[52] Hong Kong Electrical and Mechanical Services Department, Performance-based Building Energy Code 2007, Hong Kong, 2007. https://www.emsd.gov.hk/filemanager/en/content_725/PBBEC_Guidelines_2007.pdf.

[53] J. Burgess, C.M. Harrison, P. Filius, Environmental communication and the cultural politics of environmental citizenship, Environ. Plan. A. 30 (1998) 1445-1460. doi:10.1068/a301445.

[54] I. Ajzen, M. Fishbein, Understanding attitudes and predicting social behaviour, (1980). http://www.citeulike.org/group/38/article/235626.

[55] P.C. Stern, Toward a Coherent Theory of Environmentally Significant Behavior: EBSCOhost, J. Soc. Issues. 563 (2000) 407-424. doi:10.1007/BF00640994. 
[56] G. Spaargaren, B. Van Vliet, Lifestyles, consumption and the environment: The ecological modernisation of domestic consumption, Env. Polit. 9 (2000) 50-76. doi:10.1080/09644010008414512.

[57] J.T. Folke ölander, Understanding of Consumer Behaviour as a Prerequisite for Environmental Protection, J. Consum. Policy. 18 (1995) 345-385. doi:10.1007/BF01024160.

[58] L. Steg, C. Vlek, Encouraging pro-environmental behaviour: An integrative review and research agenda, J. Environ. Psychol. 29 (2009) 309-317.

[59] W. Abrahamse, L. Steg, C. Vlek, T. Rothengatter, A review of intervention studies aimed at household energy conservation, J. Environ. Psychol. 25 (2005) 273-291.

[60] P.K. Lehman, E.S. Geller, Behavior analysis and environmental protection: Accomplishments and potential for more, Behav. Soc. Issues. 13 (2004) 13-32.

[61] Schultz, Power_of_Social_Norms, Psycological Sci. 18 (2007) 429-434. https://www.jsmf.org/meetings/2008/july/social norms Cialdini.pdf.

[62] S.C. Staddon, C. Cycil, M. Goulden, C. Leygue, A. Spence, Intervening to change behaviour and save energy in the workplace: A systematic review of available evidence, Energy Res. Soc. Sci. 17 (2016) 30-51. doi:10.1016/j.erss.2016.03.027.

[63] L. Gynther, I. Mikkonen, A. Smits, Evaluation of European energy behavioural change programmes, Energy Effic. 5 (2012) 67-82. doi:10.1007/s12053-011-9115-9.

[64] M. Moezzi, Behavioral Assumptions in Energy Efficiency Potential Studies, California Institute for Energy and Environment, Oakland, CA, 2009.

[65] J. Henryson, T. Hakansson, J. Pyrko, Energy efficiency in buildings through information-Swedish perspective, Energy Policy. 28 (2000) 169-180.

[66] R.A. Winett, P. Ester, Behavioral science and energy conservation: Conceptualizations, strategies, outcomes, energy policy applications, J. Econ. Psychol. 3 (1983) 203-229. doi:https://doi.org/10.1016/0167-4870(83)90003-X.

[67] K. Philip, Principles of marketing, 2002.

[68] H. Staats, P. Harland, H.A.M. Wilke, Effecting Durable Change: A Team Approach to Improve Environmental Behavior in the Household, Environ. Behav. 36 (2004) 341-367.

[69] A.\& H. Booz, The Low Cost/No Cost Energy Conservation Program in New England: An Evaluation, Washington, D.C., 1980.

[70] T. Owen, A. Pape-Salmon, B. McMurchy, Employee engagement and energy information software supporting carbon neutrality, Proc. 2010 ACEEE Summer Study Energy Effic. Build. (2010) 233-244.

[71] C. Gustafson, M. Longland, B.C. Hydro, Engaging employees in conservation leadership, Proc. 2008 ACEEE Summer Study Energy Effic. Build. (2008) 7-134.

[72] T. Hargreaves, Practice-ing behaviour change: Applying social practice theory to pro-environmental behaviour change, J. Consum. Cult. 11 (2011) 79-99. doi:10.1177/1469540510390500.

[73] W.S. Jevons, The Coal Question; An Inquiry Concerning the Progress of the Nation, and the Probable 
Exhaustion of our Coal-Mines., Fortnightly. 6 (1866) 505-507.

[74] A.R. Carrico, M. Riemer, Motivating energy conservation in the workplace: An evaluation of the use of group-level feedback and peer education, J. Environ. Psychol. 31 (2011) 1-13.

[75] C. Seligman, J.M. Darley, Feedback as a means of decreasing residential energy consumption., J. Appl. Psychol. 62 (1977) 363-368. doi:10.1037/0021-9010.62.4.363.

[76] A. Faruqui, S. Sergici, A. Sharif, The impact of informational feedback on energy consumption--A survey of the experimental evidence, Energy. 35 (2010) 1598-1608.

[77] G. Peschiera, J.E. Taylor, J.A. Siegel, Response-Relapse Patterns of Building Occupant Electricity Consumption following Exposure to Personal, Contextualized and Occupant Peer Network Utilization Data, Energy Build. 42 (2010) 1329-1336.

[78] C.A. Insko, Balance theory and phenomenology, Cogn. Responses Persuas. (1981) 309-338.

[79] S.C. Staddon, C. Cycil, M. Goulden, C. Leygue, A. Spence, Intervening to change behaviour and save energy in the workplace: A systematic review of available evidence, Energy Res. Soc. Sci. 17 (2016) 30-51. doi:10.1016/j.erss.2016.03.027.

[80] L. Gynther, I. Mikkonen, A. Smits, Evaluation of European energy behavioural change programmes, Energy Effic. 5 (2012) 67-82. doi:10.1007/s12053-011-9115-9.

[81] H. Staats, E. van Leeuwen, A. Wit, A Longitudinal Study of Informational Interventions to Save Energy in an Office Building., J. Appl. Behav. Anal. 33 (2000) 101-104.

[82] M.A. Delmas, M. Fischlein, O.I. Asensio, Information strategies and energy conservation behavior: A meta-analysis of experimental studies from 1975 to 2012, Energy Policy. 61 (2013) 729-739.

[83] R.D. Katzev, T.R. Johnson, Comparing the Effects of Monetary Incentives and Foot-in-the-Door Strategies in Promoting Residential Electricity Conservation, J. Appl. Soc. Psychol. 14 (1984) 12-27. doi:10.1111/j.1559-1816.1984.tb02217.x.

[84] J. McDonald, Niamh and Laustsen, A comparative analysis of building energy efficiency policies for new buildings, G. (2013).

[85] T. Zhao, L. Bell, M.W. Horner, J. Sulik, J. Zhang, Consumer responses towards home energy financial incentives: A survey-based study, Energy Policy. 47 (2012) 291-297. doi:10.1016/j.enpol.2012.04.070.

[86] M. Baldini, A. Trivella, J.W. Wente, The impact of socioeconomic and behavioural factors for purchasing energy efficient household appliances: A case study for Denmark, Energy Policy. 120 (2018) 503-513. doi:10.1016/j.enpol.2018.05.048.

[87] A. Alberini, A. Bigano, How effective are energy-efficiency incentive programs? Evidence from Italian homeowners, Energy Econ. 52 (2015) S76-S85. doi:10.1016/j.eneco.2015.08.021.

[88] K. Gillingham, K. Palmery, Bridging the energy efficiency gap: Policy insights from economic theory and empirical evidence, Rev. Environ. Econ. Policy. 8 (2014) 18-38. doi:10.1093/reep/ret021.

[89] I. Ajzen, The theory of planned behavior, Organ. Behav. Hum. Decis. Process. 211 (1991) 179-211. doi:10.4135/9781446249215.n22. 
[90] G.D. Lynne, C. Franklin Casey, A. Hodges, M. Rahmani, Conservation technology adoption decisions and the theory of planned behavior, J. Econ. Psychol. 16 (1995) 581-598. doi:10.1016/01674870(95)00031-6.

[91] U.S. Department of Energy, Federal Energy Management Program, 2016. (2016). https://www.energy.gov/sites/prod/files/2016/02/f29/fed_energy_mgmt_program.pdf.

[92] U.S. Department of Energy, Federal Energy Management Program Building Energy Intensity Reduction, (n.d.).

https://www4.eere.energy.gov/femp/requirements/laws_and_requirements/building_energy_intensity_r eduction_1.

[93] N. Borg, Y. Blume, S. Thomas, W. Irrek, H. Faninger-Lund, P. Lund, A. Pindar, Release the power of the public purse, Energy Policy. 34 (2006) 238-250. doi:10.1016/J.ENPOL.2004.08.027.

[94] E. Martinot, N. Borg, Energy-efficient lighting programs, Energy Policy. 26 (1998) 1071-1081. doi:10.1016/s0301-4215(98)00052-4.

[95] K. Lo, A critical review of China's rapidly developing renewable energy and energy efficiency policies, Renew. Sustain. Energy Rev. 29 (2014) 508-516. doi:10.1016/J.RSER.2013.09.006.

[96] J. Ministry of Economy Trade and Industry, Implementation Status of the Program to Promote the Spread of Green Home Appliances by Utilizing Eco-Points, 2013. (n.d.). http://www.meti.go.jp/english/press/data/20100713_01.html.

[97] G. Du, W. Lin, C. Sun, D. Zhang, Residential electricity consumption after the reform of tiered pricing for household electricity in China, Appl. Energy. 157 (2015) 276-283. doi:10.1016/J.APENERGY.2015.08.003.

[98] G. Du, W. Lin, C. Sun, D. Zhang, Residential electricity consumption after the reform of tiered pricing for household electricity in China, Appl. Energy. 157 (2015) 276-283. doi:10.1016/J.APENERGY.2015.08.003.

[99] B. Lin, Z. Jiang, Estimates of energy subsidies in China and impact of energy subsidy reform, Energy Econ. 33 (2011) 273-283. doi:10.1016/J.ENECO.2010.07.005.

[100] C. Wang, K. Zhou, S. Yang, A review of residential tiered electricity pricing in China, Renew. Sustain. Energy Rev. 79 (2017) 533-543. doi:10.1016/J.RSER.2017.05.097.

[101] H. Lin, Q. Wang, Y. Wang, R. Wennerstern, Agent-based Modeling of Electricity Consumption in an Office Building under a Tiered Pricing Mechanism, Energy Procedia. 104 (2016) 329-335. doi:10.1016/J.EGYPRO.2016.12.056.

[102] T.A. Heberlein, G.K. Warriner, The influence of price and attitude on shifting residential electricity consumption from on- to off-peak periods, J. Econ. Psychol. 4 (1983) 107-130. doi:10.1016/01674870(83)90048-X.

[103] S. Huang, B.-M.S. Hodge, F. Taheripour, J.F. Pekny, G. V. Reklaitis, W.E. Tyner, The effects of electricity pricing on PHEV competitiveness, Energy Policy. 39 (2011) 1552-1561. doi:10.1016/J.ENPOL.2010.12.029. 
[104] A.J. Black, Financial payback on California residential solar electric systems, Sol. Energy. 77 (2004) 381-388. doi:10.1016/J.SOLENER.2004.02.003.

[105] M. Muratori, G. Rizzoni, Residential Demand Response: Dynamic Energy Management and TimeVarying Electricity Pricing, IEEE Trans. Power Syst. 31 (2016) 1108-1117. doi:10.1109/TPWRS.2015.2414880.

[106] J. Torriti, M.G. Hassan, M. Leach, Demand response experience in Europe: Policies, programmes and implementation, Energy. 35 (2010) 1575-1583. doi:10.1016/J.ENERGY.2009.05.021.

[107] J.D. Khazzoom, Economic Implications of Mandated Efficiency in Standards for Household Appliances, Energy J. Volume 1 (1980) 21-40. https://econpapers.repec.org/RePEc:aen:journl:1980v01-04-a02.

[108] S. Guo, D. Yan, S. Hu, The Rebound Effect in District Cooling Systems : Analysis Based on Case Studies and Surveys in China, in: ACEEE Summer Study Build. Energy, 2016: pp. 1-11.

[109] J.S. Scott Murtishaw, Quantifying the Effect of the Principal-Agent Problem on U.S. Residential Energy Use, in: ACEEE, 2008: pp. 293-304. https://aceee.org/files/proceedings/2008/data/papers/9_59.pdf.

[110] Oxera Consulting Ltd, Policies for energy efficiency in the UK household sector Report prepared for Defra, (2006) 117. http://www.oxera.com/Oxera/media/Oxera/Policies-for-energy-efficiency-in-theUK-household.pdf?ext=.pdf.

[111] G. Kelly, Sustainability at home: Policy measures for energy-efficient appliances, Renew. Sustain. Energy Rev. 16 (2012) 6851-6860. doi:10.1016/J.RSER.2012.08.003.

[112] S. D’Oca, T. Hong, J. Langevin, The human dimensions of energy use in buildings: A review, Renew. Sustain. ENERGY Rev. 81 (2018) 731-742. doi:10.1016/j.rser.2017.08.019.

[113] D. Yan, W.O. Brien, T. Hong, X. Feng, H.B. Gunay, F. Tahmasebi, A. Mahdavi, Occupant behavior modeling for building performance simulation : Current state and future challenges, 107 (2015) 264278. doi:10.1016/j.enbuild.2015.08.032.

[114] Z. Yu, B.C.M. Fung, F. Haghighat, H. Yoshino, E. Morofsky, A systematic procedure to study the influence of occupant behavior on building energy consumption, Energy Build. (2011). doi:10.1016/j.enbuild.2011.02.002.

[115] A. Wagner, W. O’Brien, B. Dong, Exploring Occupant Behavior in Buildings: Methods and Challenges, Spinger, 2018. doi:10.1007/978-3-319-61464-9.

[116] B. Dong, V. Prakash, F. Feng, Z. O'Neill, A review of smart building sensing system for better indoor environment control, Energy Build. 199 (2019) 29-46. doi:10.1016/j.enbuild.2019.06.025.

[117] T. Hong, S.C. Taylor-Lange, S. D’Oca, D. Yan, S.P. Corgnati, Advances in research and applications of energy-related occupant behavior in buildings, Energy Build. 116 (2016) 694-702. doi:https://doi.org/10.1016/j.enbuild.2015.11.052.

[118] L.A. Tagliafico, P. Cavalletti, C. Fabbri, F. Scarpa, Dynamic Behaviour and Control Strategy Optimization for Conventional Heating Plants in Buildings, Int. J. HEAT Technol. 34 (2016) S505- 
S511. doi:10.18280/ijht.34S244.

[119] P. Boonma, J. Suzuki, Exploring Self-star Properties in Cognitive Sensor Networking, in: Obaidat, MS and Marzo, JL and Szczerbicka, H and Vila, P (Ed.), Proc. 2008 Int. Symp. Perform. Eval. Comput. Telecommun. Syst., SOC MODELING SIMULATION INT-SCS, PO BOX 17900, SAN DIEGO, CA 92177 USA, 2008: pp. 36-43.

[120] V. Motuziene, T. Vilutiene, Modelling the effect of the domestic occupancy profiles on predicted energy demand of the energy efficient house, in: Procedia Eng., 2013.

doi:10.1016/j.proeng.2013.04.101.

[121] B. Gucyeter, Evaluating diverse patterns of occupant behavior regarding control-based activities in energy performance simulation, Front. Archit. Res. (2018). doi:10.1016/j.foar.2018.03.002.

[122] Y.S. Lee, A.M. Malkawi, Simulating multiple occupant behaviors in buildings: An agent-based modeling approach, Energy Build. (2014). doi:10.1016/j.enbuild.2013.11.020.

[123] G.Y. Yun, K. Steemers, Time-dependent occupant behaviour models of window control in summer, Build. Environ. (2008). doi:10.1016/j.buildenv.2007.08.001.

[124] H.B. Gunay, W. O’Brien, I. Beausoleil-Morrison, A critical review of observation studies, modeling, and simulation of adaptive occupant behaviors in offices, Build. Environ. (2013). doi:10.1016/j.buildenv.2013.07.020.

[125] J. Virote, R. Neves-Silva, Stochastic models for building energy prediction based on occupant behavior assessment, Energy Build. (2012). doi:10.1016/j.enbuild.2012.06.001.

[126] R.V. Andersen, J. Toftum, K.K. Andersen, B.W. Olesen, Survey of occupant behaviour and control of indoor environment in Danish dwellings, Energy Build. 41 (2009) 11-16. doi:10.1016/j.enbuild.2008.07.004.

[127] A.C. Menezes, A. Cripps, D. Bouchlaghem, R. Buswell, Predicted vs. actual energy performance of non-domestic buildings: Using post-occupancy evaluation data to reduce the performance gap, Appl. Energy. (2012). doi:10.1016/j.apenergy.2011.11.075.

[128] S. D'Oca, T. Hong, Occupancy schedules learning process through a data mining framework, Energy Build. (2015). doi:10.1016/j.enbuild.2014.11.065.

[129] K.U. Ahn, C.S. Park, Correlation between occupants and energy consumption, Energy Build. (2016). doi:10.1016/j.enbuild.2016.01.010.

[130] H. Herring, Energy efficiency : a critical view, Energy. 31 (2006) 10-20. https://doi.org/10.1016/j.energy.2004.04.055.

[131] S. Darby, Enough is as good as a feast - sufficiency as policy, in: Eur. Counc. an Energy-Efficient Econ. 2017 Summer Study, 2007: pp. 111-119.

[132] T. Fawcett, S. Darby, Energy sufficiency : an introduction Concept paper, (2018). doi:10.13140/RG.2.2.31198.08006.

[133] IPCC, IPCC Fifth Assessment Report, 2014. https://www.ipcc.ch/assessment-report/ar5/.

[134] L. Yang, J. Xia, Q. Shen, Establishing target-oriented energy consumption quotas for buildings, Util. 
Policy. 41 (2016) 57-66. doi:10.1016/j.jup.2016.06.001. 